\title{
STATIC NON-LINEAR THREE-DIMENSIONAL ANALYSIS OF A RISER BUNDLE BY A SUBSTRUCTURING AND INCREMENTAL FINITE ELEMENT ALGORITHM
}

\author{
MICHAEL M. BERNITSAS* AND NICKOLAS VLAHOPOULOS ${ }^{*}$ \\ Department of Naval Architecture and Marine Engineering, The University of Michigan, Ann Arbor, Michigan \\ 48109-2145, U.S.A.
}

\begin{abstract}
SUMMARY
The problem of static, non-linear, large three-dimensional deformation of riser bundles used in offshore oil and gas production is studied within the limits of small strain theory. The mathematical model consists of the models of component-risers and connectors which hold risers together. Each riser is modelled as a thin walled, slender, extensible or inextensible tubular beam-column. It is subject to non-linear three-dimensional deformation dependent hydrodynamic loads, torsion and distributed moments, varying axial tension, and internal and external fluid forces. The problem is solved numerically by developing an algorithm which features substructuring, condensation and non-linear incremental finite elements. Substructuring is used to decompose the riser bundle problem into those of individual component-risers and equilibria of connectors. Condensation is used along with the connector equilibrium equations to produce connector forces and moments. Strong non-linearities present in the model are handled by an incremental finite element approach. Accuracy of the computer code is verified by solving simple three-dimensional cases. Two three-dimensional applications are solved for a bundle with seven component-risers and up to a total of 1267 degrees of freedom. Finally, a comparison is made with numerical results of a two-dimensional analysis code. The influence of problem size on total CPU time is discussed.
\end{abstract}

\section{INTRODUCTION}

A production riser, used in offshore oil and gas production, is a bundle of several component-risers which are interconnected by guide arms. Each component-riser is a tubular structure connecting a well head at the ocean bed to the supporting offshore platform, and in current practice may be as long as $2000 \mathrm{~m}$. Guide arms serve simultaneously as connectors and spacers since they keep component-risers apart to prevent damage from collision. Production risers may be in integral or non-integral form, depending on the number and kind of geometric constraints imposed on the degrees of freedom of individual component-risers by the guide arms. These structures are described in References 1,2,3 and 4. In integral systems connectors restrain both deflections and rotations of connected nodes. Composite models are used for analysis of integral risers as shown in References 1 and 3. Non-integral systems allow for more flexibility of component-risers and cannot be solved by composite models. A dedicated algorithm must be developed like those described in References 1 and 5. A non-integral system and its cross section are depicted in

\footnotetext{
* Associate Professor

" Project Engineer in Automated Analysis Corporation, Ann Arbor, MI
}

0029-5981/89/122517-24\$12.00

(C) 1989 by John Wiley \& Sons, Ltd.
Received 2 Scptember 1988

Revised 13 February 1989 
Figures 1 and 2 respectively. It is composed of a central riser on which guide arms are welded and several peripheral risers which pass through the guide arm funnels.

Finite element techniques are used to analyse single riser structures. ${ }^{6,7}$ Bundles of risers have high number of components and consequently a very high number of finite elements and degrees of freedom. For this reason solution of non-integral production riser problem by direct application of a finite element method becomes expensive and time consuming. Substructuring techniques for static and dynamic analyses ${ }^{8}$ and for eigenanalysis ${ }^{9}$ are appropriate to use for riser bundles which are large structural systems with several distinct substructures. The problems of static, dynamic and eigenanalysis of non-integral production risers in planar deformation have been solved in Reference 5. In that case substructures, that is component risers, have exactly the same values of degrees of freedom at interfaces. Thus, substructuring and condensation can be directly used in planar riser deformation problems. In three-dimensional problems, like the one studied in this paper, interfaces between component risers do not have identical values of degrees of freedom. Guide arms impose geometric constraints on interface degrees of freedom which must be used along with the equations of equilibrium of connectors in order to achieve substructuring and condensation.

A mathematical model of a riser bundle is presented in Section 2 and consists of a static nonlinear large three-dimensional deformation model for each component-riser, its boundary

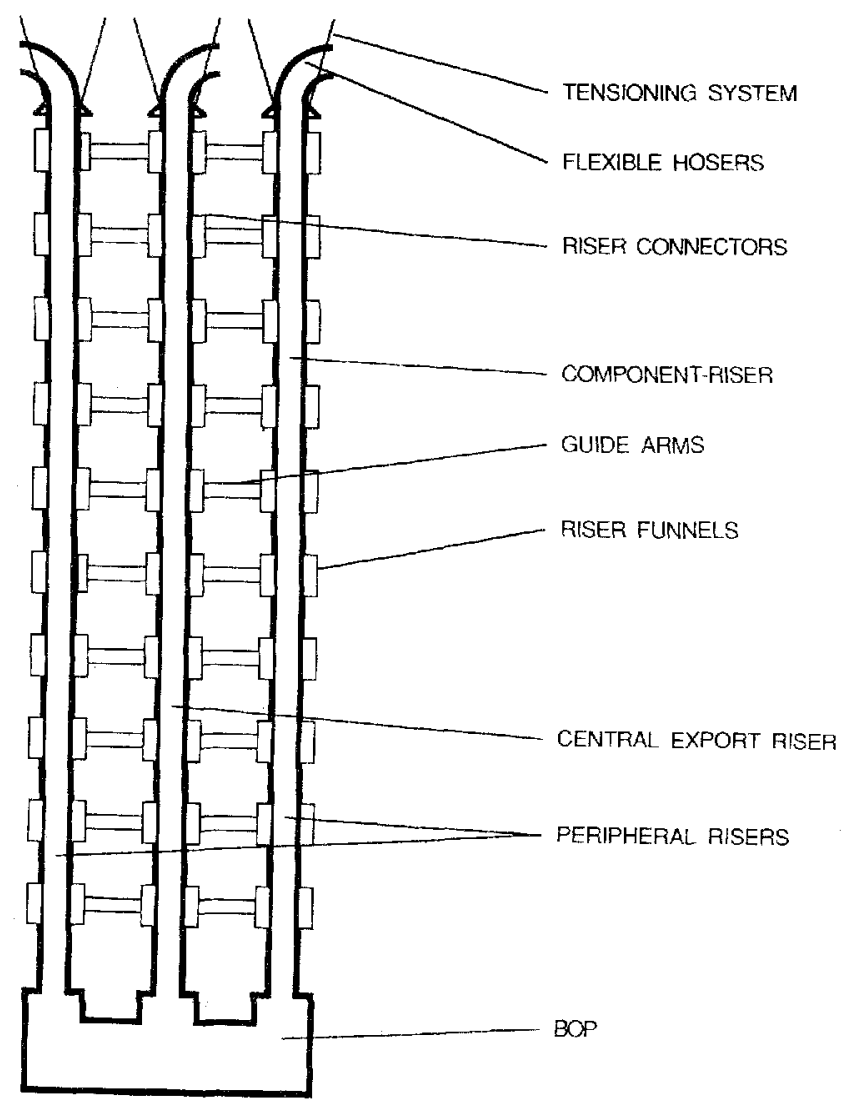

Figure 1. Non-integral production riser 


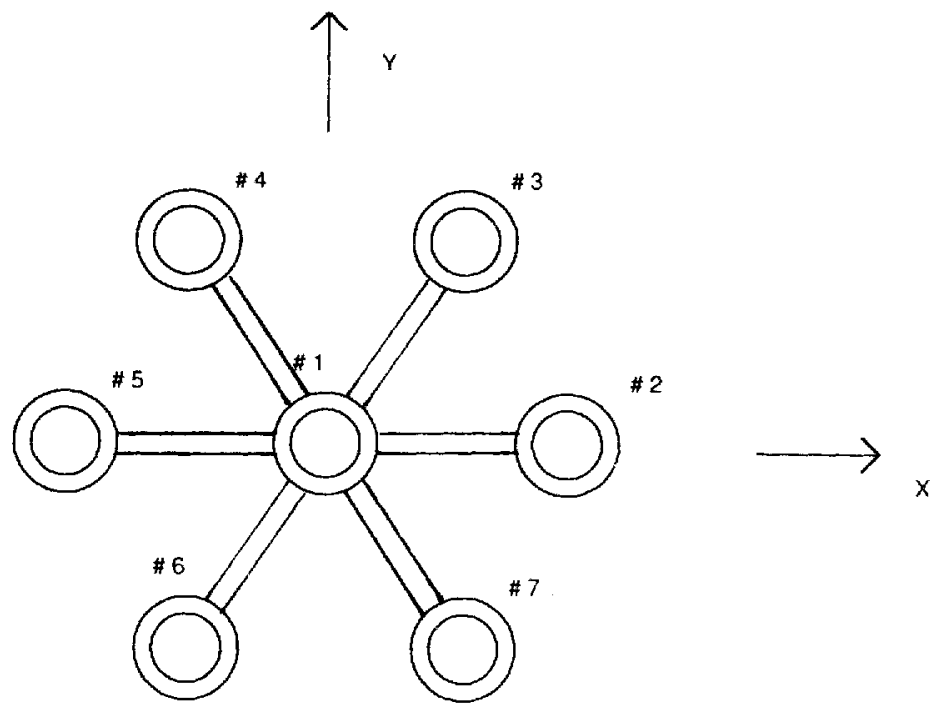

Figure 2. Cross section of non-integral production riser

conditions, and constraints imposed by guide arms. A solution method is developed in Section 3 and consists of an incremental finite element algorithm and a substructuring condensation algorithm. In Section 4 simple verification cases are used to test the computer program's accuracy and several applications with up to 1267 degrees of freedom are used to illustrate the program's efficiency in practical applications.

\section{MATHEMATICAL MODEL}

The mathematical model of a riser bundle is comprised of the model of each component-riser and its boundary conditions, and constraints imposed by guide arms. A typical non-integral riser bundle and its cross section are shown in Figures 1 and 2. It is assumed that the riser material is homogeneous isotropic and linearly elastic. Further, the following assumptions are made.

(i) Risers are thin walled tubular columns.

(ii) Risers are locally stiff so that plane sections remain plain after bending.

(iii) Shear deformation is neglected.

(iv) In the unloaded condition risers are assumed to be straight and free of structural imperfections.

(v) Riser cross sections have equal principal stiffnesses.

(vi) Risers are restrained axially at their lower end, and they may be extensible or inextensible.

(vii) Guide arms are rigid and welded on the central riser (\#1 in Figure 1). Only relative translations of peripheral risers are restrained by guide arms. Rotations are not restrained.

(viii) Friction of peripheral risers due to their motion in guide funnels is neglected. Thus the interaction force between a peripheral riser and a guide arm is normal to the riser centreline.

(ix) Risers are subject to external hydrostatic pressure and internal static pressure due to drilling or production fluid. 
On the basis of the above assumptions we can use the following mathematical model developed for a single riser by Nordgren ${ }^{10}$ and Bernitsas et al. ${ }^{6,11}$ The geometry of the riser axis in the deformed and undeformed states is depicted in Figure 3. Notation for forces and moments is shown in Figure 4. Equilibrium of forces and moments yield respectively

$$
\mathbf{F}^{\prime}+\mathbf{q}=\mathbf{0}
$$

and

$$
\mathbf{M}^{\prime}+(\hat{t} \times \mathbf{F})+\mathbf{m}=\mathbf{0}
$$

where $\mathbf{F}=\left(F_{1}, F_{2}, F_{3}\right)$ and $\mathbf{M}=\left(M_{1}, M_{2}, M_{3}\right)$ are internal force and moment vectors respectively; $\mathbf{q}$ and $\mathbf{m}$ are applied force and moment per unit length; $(\hat{t}, \hat{n}, \hat{b})$ is the triad of local principal unit vectors of the riser centreline

$$
\hat{t}=\mathbf{r}^{\prime}, \quad \hat{b}=\mathbf{r}^{\prime} \times \mathbf{r}^{\prime \prime} / \kappa, \quad \kappa=\left|\mathbf{r}^{\prime \prime}\right|
$$

$\therefore$ indicates unit vector and the differential operator is $\mathrm{d} / \mathrm{d} s_{1}$ with respect to the arc length $s_{1}$ of the deformed riser centreline. $k$ is the principal local curvature. The constitutive equation for bending and torsion is

$$
\mathbf{M}=B \kappa \hat{b}+H \hat{t}
$$

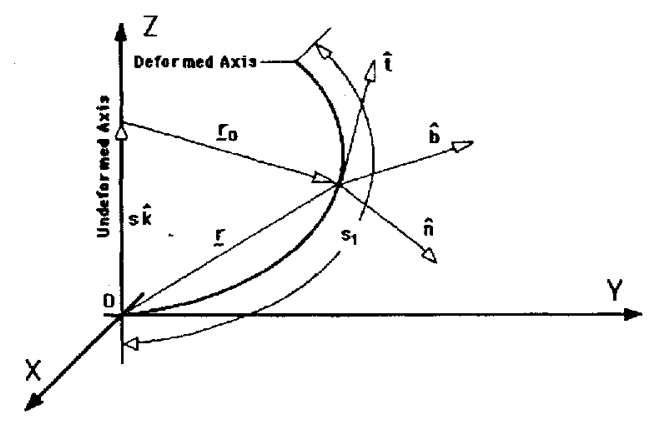

Figure 3. Position vector and principle directions of a single riser

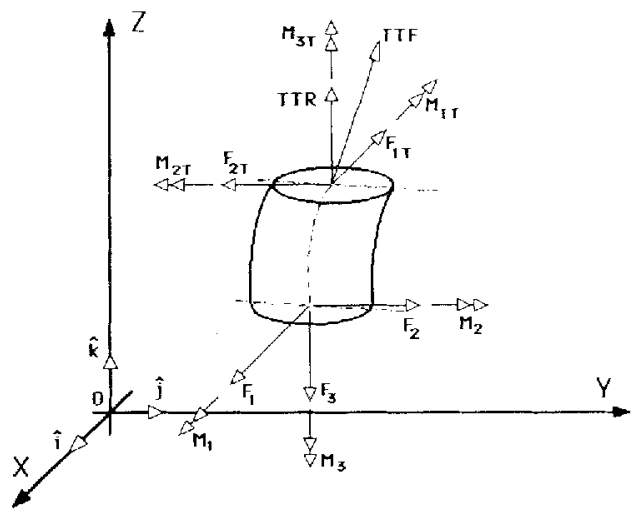

Figure 4. Differential element of riser upper end: free body diagram 
where $B=E I$ is the bending rigidity and $H$ is torsional moment. Combining equations (1), (2), (3) and (4) we get the governing equations:

for bending

$$
-\left(B \mathbf{r}^{\prime \prime}\right)^{\prime \prime}+\left[\left(T_{\mathrm{e}}-B \kappa^{2}\right) \mathbf{r}^{\prime}\right]^{\prime}+\left[H\left(\mathbf{r}^{\prime} \times \mathbf{r}^{\prime \prime}\right)\right]^{\prime}+\left(\mathbf{r}^{\prime} \times \mathbf{m}\right)^{\prime}+\mathbf{q}=\mathbf{0}
$$

and for torsion

$$
H^{\prime}+\hat{t} \cdot \mathbf{m}=0
$$

In the above equations the position vector $\mathbf{r}$ shown in Figure 3 is

$$
\mathbf{r}=x_{1} \hat{i}+x_{2} \hat{j}+\left(x_{3}+s\right) \hat{k}
$$

where $s$ is the arc length of the riser centreline measured in the initial unstrained state, the effective tension $T_{\mathrm{e}}$ is

$$
T_{\mathrm{e}}=T+\rho_{\mathrm{w}} g \frac{\pi D_{\mathrm{o}}^{2}}{4}\left[H_{\mathrm{w}}-\left(x_{3}+s\right)\right]-\rho_{\mathrm{i}} g \frac{\pi D_{\mathrm{i}}^{2}}{4}\left[H_{\mathrm{i}}-\left(x_{3}+s\right)\right]
$$

$T$ is the actual tension in the riser, $H_{\mathrm{w}}$ and $H_{\mathrm{i}}$ are the $z$ co-ordinates of water and internal fluid free surface, $\rho_{\mathrm{w}}$ and $\rho_{\mathrm{i}}$ are densities of water and internal fluid, $D_{\mathrm{o}}$ and $D_{\mathrm{i}}$ are external and internal riser diameters, and $z=\left(x_{3}+s\right)$ is measured from the riser lower end. The actual tension $T$ satisfies the constitutive equation

$$
T=E A \varepsilon_{t}
$$

where $E A$ is the stretching rigidity and $\varepsilon_{t}$ the strain of the riser centreline in the tangential direction defined as

$$
\varepsilon_{f}=\left|\frac{\mathrm{d} \mathbf{r}}{\mathrm{d} s} \cdot \frac{\mathrm{d} \mathbf{r}}{\mathrm{d} s}\right|^{1 / 2}-1
$$

where $s$ and $s_{1}$ are related by

$$
\frac{\mathrm{d} s_{1}}{\mathrm{~d} s}=1+\varepsilon_{\mathrm{t}}
$$

The effective tension $T_{\mathrm{e}}$ is the tangential component of the internal force $\mathbf{F}$, which can be derived by integration of equation (1). Since the effective tension is used in this formulation the vertical component of $q$ should include the effective riser weight, $W_{\mathrm{e}}$, per unit length defined as the weight of riser plus contents in water. ${ }^{6}$ The hydrodynamic components of the external force $q$ are

$$
\mathbf{q}_{\mathrm{H}}\left(s_{1}\right)=\left\{\begin{array}{l}
q_{\mathrm{H}_{1}} \\
q_{\mathrm{H}_{2}} \\
q_{\mathbf{H}_{3}}
\end{array}\right\}=\frac{1}{2} \rho_{\mathrm{w}} C_{\mathrm{D}} D_{\mathrm{H}}\left|\mathbf{V}_{n}\right|\left\{\begin{array}{l}
V_{n_{1}} \\
V_{n_{2}} \\
V_{n_{3}}
\end{array}\right\}
$$

where only the drag term is considered in the Morrison-Borgman formula, ${ }^{12,13} C_{\mathrm{D}}$ is drag coefficient, $D_{\mathrm{H}}$ is hydrodynamic diameter and $\mathbf{V}_{n}$ is the component of the relative flow velocity normal to the riser centreline. Values of $C_{D}$ for single or multiple riser structures can be found in the literature. ${ }^{14-18}$

Moment $\mathbf{m}\left(s_{1}\right)$ arises from asymmetry in the relative flow due to vortex sedding and the geometry of the riser bundle. Torque is also induced by imperfections in the tensioning system and the lower ball joint. The most significant torque component in the riser bundle is exerted on the central riser by the other risers through connectors. Boundary conditions are needed for 
completion of the mathematical model of each component riser. The following five must be defined:

(i) $\hat{t} \times \mathbf{M}$ or $\mathbf{r}^{\prime}$ at $s_{1}=0$,

(ii) $\hat{t} \times \mathbf{M}$ or $\mathbf{r}^{\prime}$ at the upper end,

(iii) $\mathbf{F}$ or $\mathbf{r}$ at $s_{1}=0$,

(iv) $\mathbf{F}$ or $\mathbf{r}$ at the upper end, and

(v) the torsional moment at the lower or upper end.

Pressure forces are non-conservative (follower forces) and therefore special attention is required to write boundary conditions at the upper riser end. Equilibrium of forces applied at the upper riser end differential element, as shown in Figure 4, yields

where

$$
\begin{aligned}
& F_{x, \mathrm{u}}=\operatorname{TTF}(\hat{t} \cdot \hat{i})-K_{x} x_{1, \mathrm{u}} \\
& F_{y, \mathrm{u}}=\operatorname{TTF}(\hat{t} \cdot \hat{j})-K_{y} x_{2, \mathrm{u}} \\
& F_{z, \mathrm{u}}=\operatorname{TTF}(\hat{t} \cdot \hat{k})+\operatorname{TTR}
\end{aligned}
$$

$$
\mathrm{TTF}=\rho_{\mathrm{w}} g \frac{\pi D_{\mathrm{o}, \mathrm{u}}^{2}}{4}\left[H_{\mathrm{w}}-z_{\mathrm{u}}\right]-\rho_{\mathrm{m}} g \frac{\pi D_{\mathrm{i}, \mathrm{u}}^{2}}{4}\left[H_{\mathrm{m}}-z_{\mathrm{u}}\right]
$$

TTR is the tension applied at the top of each component-riser by its tensioning system, $K_{x}$ and $K_{y}$ are linear spring constants and subscript $u$ indicates the upper riser end. It should be noted that the fluid pressure force TTF and its direction of application are deformation dependent.

The equations of equilibrium of riser connectors are needed in order to complete the riser bundle model. To be able to describe the geometry of connectors and write the equations of equilibrium the following symbols are defined:

$j=1,2, \ldots, J$

$k=1,2, \ldots, K$

$j$ is the riser number and $J$ is the number of risers in the bundle;

$k$ is the connector number and $K$ is the number of connectors in the bundle;

$\left({ }_{j}^{0} \hat{t}^{k},{ }_{j}^{0} \hat{n}^{k}, \underset{j}{0} \hat{b}^{k}\right),\left(\hat{t}^{k},{ }_{j} \hat{n}^{k}, \hat{b}^{k}\right)$

are the principal unit normal triads of the $j$ th riser at the $k$ th connector in the initial undeformed and deformed states respectively; ${ }_{i}^{0} \mathbf{d}^{k}, \mathbf{d}^{k}$ are the position vectors of the $j$ th funnel in the plane of the $k$ th connector in the initial undeformed and deformed states respectively, where the origin is placed at the centre of riser \# 1 (see Figure 2);

${ }_{j} \mathbf{A} \mathbf{F}^{k}{ }_{j} \mathbf{A} \mathbf{M}^{k}$ are the force and moment vectors exerted by the $k$ th connector on the $j$ th riser. The purpose of $A$ is to indicate that these connector forces and moments are exerted in addition to the external riser load.

The equation of equilibrium of forces for the $k$ th connector is

$$
\sum_{j=1}^{J} j_{j} \mathbf{A F}^{k}=\mathbf{0}
$$

The equation of equilibrium of moments for the $k$ th connector is

$$
\sum_{j=1}^{J}\left({ }_{j} \mathbf{d}^{k} \times{ }_{j} \mathbf{A} \mathbf{F}^{k}+{ }_{j} \mathbf{A} \mathbf{M}^{k}\right)=\mathbf{0}
$$

Since ${ }_{1} \mathbf{d}^{k}=\mathbf{0}$ and ${ }_{j} \mathbf{A} \mathbf{M}^{k}=\mathbf{0}$ for $j=2, \ldots, J$ because of assumption (vii), the previous equation is reduced to

$$
\sum_{j=2}^{J}\left({ }_{j} \mathbf{d}^{k} \times{ }_{j} \mathbf{A F}{ }^{k}\right)+{ }_{1} \mathbf{A} \mathbf{M}^{k}=\mathbf{0}
$$


Assumption (viii) dictates that

$$
\hat{i}^{k} \cdot{ }_{j} \mathbf{A F}^{k}=0 \text { for } j=2, \ldots, J
$$

Finally, the location and orientation of each connector is needed and computed in the numerical solution using the following data:

(i) ${ }_{1} \mathbf{u}^{k}$, the deformation vector of the central riser \# 1 , at the location of the $k$ th connector. This defines the origin of the connector attached system of coordinates in space.

(ii) $\left({ }_{1} \hat{t}^{k}, \hat{n}_{1}^{k},{ }_{1} \hat{b}^{k}\right)$ which defines the orientation of the $k$ th connector in space.

(iii) ${ }_{j}^{0} \mathbf{d}^{k}$ which defines the $k$ th connector geometry, and is needed to compute ${ }_{j} \mathbf{d}^{k}$.

\section{SOLUTION METHOD}

The riser bundle problem described in Section 2 is solved by using two algorithms. The first is used for incremental application of the fluid velocity which results in incremental application of the hydrodynamic load. This algorithm is explained in Subsection 3.1. The second algorithm is used for substructuring and condensation in order to decompose the original problem into those of component-risers and connectors. In this way several small problems are solved instead of a single large finite element problem. This algorithm is developed in Subsection 3.2 .

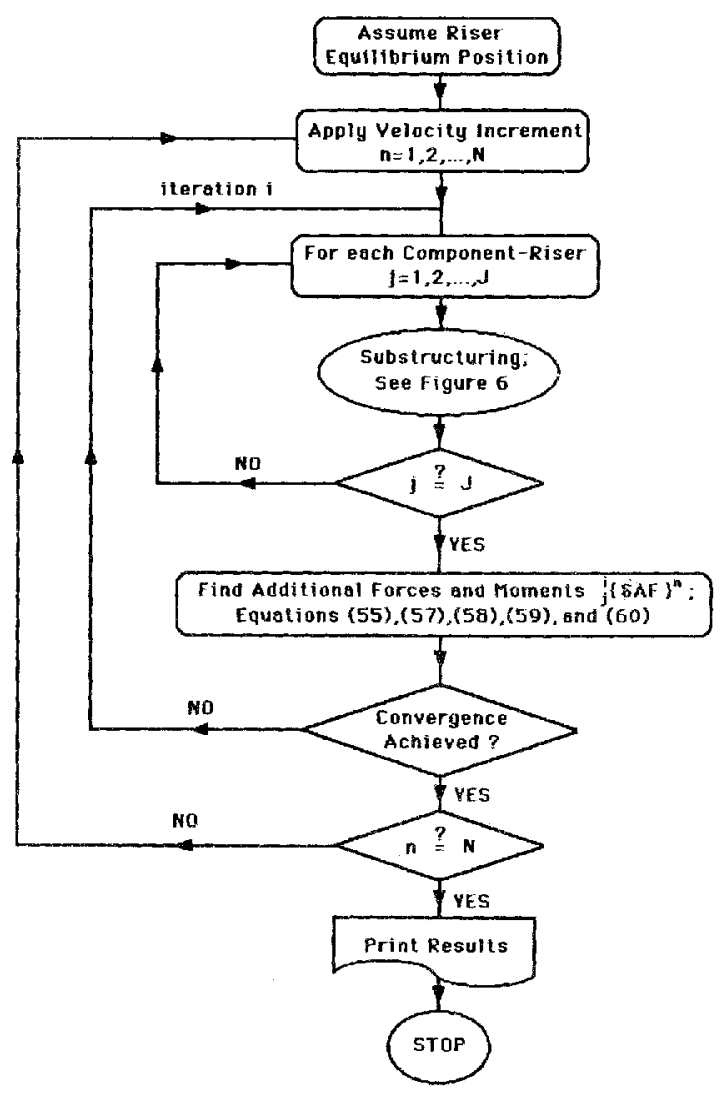

Figure 5. Solution algorithm: increments and condensation 


\subsection{Incremental algorithm}

This method is based on an incremental finite element technique. In each increment a velocity, and hence a load increment, is applied (see Figure 5). Within each increment, itcrations are performed until convergence is achieved. Within each iteration substructuring is performed after the stiffness matrices, the boundary terms, the extensibility or inextensibility condition and the deformation dependent load have been updated as shown in Figure 6.

Applying successively the principle of virtual displacements and the incremental operator $\Delta$ to equations (5) and (6) the following weak form is derived:

$$
\begin{aligned}
& B \int_{0}^{l_{1}} \Delta \mathbf{r}^{\prime \prime} \cdot \overline{\mathbf{r}}^{\prime \prime} \mathrm{d} s_{1}+\left(T_{\mathrm{e}}-B \kappa^{2}\right) \int_{0}^{l_{1}} \Delta \mathbf{r}^{\prime} \cdot \overline{\mathbf{r}}^{\prime} \mathrm{d} s_{1}+\int_{0}^{l_{1}}\left(\mathbf{F} \cdot \Delta \mathbf{r}^{\prime}\right)\left(\mathbf{r}^{\prime} \cdot \overline{\mathbf{r}}^{\prime}\right) \mathrm{d} s_{1} \\
& -2 B \int_{0}^{i_{1}}\left(\mathbf{r}^{\prime} \cdot \Delta \mathbf{r}^{\prime \prime}\right)\left(\mathbf{r}^{\prime \prime} \cdot \overline{\mathbf{r}}^{\prime}\right) \mathrm{d} s_{1}+H \int_{0}^{l_{1}}\left(\Delta \mathbf{r}^{\prime} \times \mathbf{r}^{\prime \prime}\right) \cdot \overline{\mathbf{r}}^{\prime} \mathrm{d} s_{1}+H \int_{0}^{l_{1}}\left(\mathbf{r}^{\prime} \times \Delta \mathbf{r}^{\prime \prime}\right) \cdot \overline{\mathbf{r}}^{\prime} \mathrm{d} s_{1} \\
& +\int_{0}^{l_{1}}\left(\Delta \mathbf{r}^{\prime} \times \mathbf{m}\right) \overline{\mathbf{r}}^{\prime} \mathrm{d} s_{1}+\int_{0}^{l_{1}}\left[\Delta \mathbf{r}^{\prime} \times\left(\mathbf{A} \mathbf{m}_{\mathrm{c}}^{\mathrm{b}} \delta\left(s_{1}\right)+\mathbf{A} \mathbf{m}_{\mathrm{c}}^{\mathrm{t}} \delta\left(l_{1}-s_{1}\right)\right)\right] \cdot \overline{\mathbf{r}}^{\prime} \mathrm{d} s_{1} \\
& =\int_{0}^{l_{1}}\left[\Delta \mathbf{q}+\Delta \mathbf{A} \mathbf{q}_{\mathbf{c}}^{\mathbf{b}} \delta\left(s_{1}\right)+\Delta \mathbf{A} \mathbf{q}_{\mathbf{c}}^{\mathbf{l}} \delta\left(l_{1}-s_{1}\right)\right] \cdot \overline{\mathbf{r}} \mathrm{d} s_{1} \\
& -\int_{0}^{l_{1}}\left(\Delta \mathbf{F} \cdot \mathbf{r}^{\prime}\right)\left(\mathbf{r}^{\prime} \cdot \overline{\mathbf{r}}^{\prime}\right) \mathrm{d} s_{1}-\Delta \mathbf{H} \int_{0}^{l}\left(\mathbf{r}^{\prime} \times \mathbf{r}^{\prime \prime}\right) \cdot \overline{\mathbf{r}}^{\prime} \mathrm{d} s_{1} \\
& -\int_{0}^{l_{1}}\left[\mathbf{r}^{\prime} \times\left(\Delta \mathbf{m}+\Delta \mathbf{A} \mathbf{m}_{\mathrm{c}}^{\mathrm{b}} \delta\left(s_{1}\right)+\Delta \mathbf{A} \mathbf{m}_{c}^{\mathrm{t}} \delta\left(l_{1}-s_{1}\right)\right)\right] \cdot \overline{\mathbf{r}}^{\prime} \mathrm{d} s_{1} \\
& +\left.\Delta \mathbf{F} \cdot \overline{\mathbf{r}}\right|_{0} ^{l_{1}}+\left.B \Delta \mathbf{r}^{\prime \prime} \cdot \overline{\mathbf{r}}^{\prime}\right|_{0} ^{l_{\prime}} \\
& \Delta \mathbf{H}\left(s_{1}\right)=\Delta \mathbf{H}(0)-\int_{0}^{s_{1}} \Delta \hat{\imath} \cdot\left(\mathbf{m}+\sum_{k=1}^{k_{s}} \mathbf{A} \mathbf{m}_{\mathrm{c}} \cdot \delta\left(s_{k}-s_{1}\right)\right) \mathrm{d} s_{1} \\
& \int_{0}^{s_{1}} \hat{t} \cdot\left(\Delta \mathbf{m}+\sum_{k=1}^{k_{s_{1}}} \Delta \mathbf{A} \mathbf{m}_{\mathrm{c}} \cdot \delta\left(s_{k}-s_{1}\right)\right) \mathrm{d} s_{1}
\end{aligned}
$$

and

where equations (21) and (22) have been used,

$$
\Delta \mathbf{F}=\Delta \mathbf{F}\left(l_{1}\right)-\int_{s_{1}}^{l_{1}}\left(\Delta \mathbf{q}+\sum_{k=k_{s_{1}}}^{k_{t_{1}}} \Delta \mathbf{A q} \delta\left(s_{k}-s_{1}\right)\right) \mathrm{d} s_{1}
$$

$$
\begin{aligned}
\Delta T & =\Delta \mathbf{F} \cdot \mathbf{r}^{\prime}+\mathbf{F} \cdot \Delta \mathbf{r}^{\prime} \\
\Delta \kappa^{2} & =2 \Delta \mathbf{r}^{\prime \prime} \cdot \mathbf{r}^{\prime \prime}
\end{aligned}
$$

$\overline{\mathbf{r}}$ is the virtual displacement vector,

$$
l_{1}=\int_{0}^{l}\left(1+\varepsilon_{t}\right) \mathrm{d} s
$$

and $l$ is the element length. Further, $A \mathbf{m}_{\mathrm{c}}^{\mathrm{b}}, A \mathbf{m}_{\mathrm{c}}^{\mathrm{t}}$ are the vectors of additional concentrated moments due to connectors at the bottom and top of the finite element; $A \mathbf{q}_{\mathrm{c}}^{\mathrm{b}}, A \mathbf{q}_{\mathrm{c}}^{\mathrm{t}}$ are the vectors of additional concentrated forces due to connectors at the bottom and top of the finite element; $k_{s_{1}}$ is the total number of connectors from the bottom of the riser up to $s_{1}, s_{k}$ is the location of a connector. It 


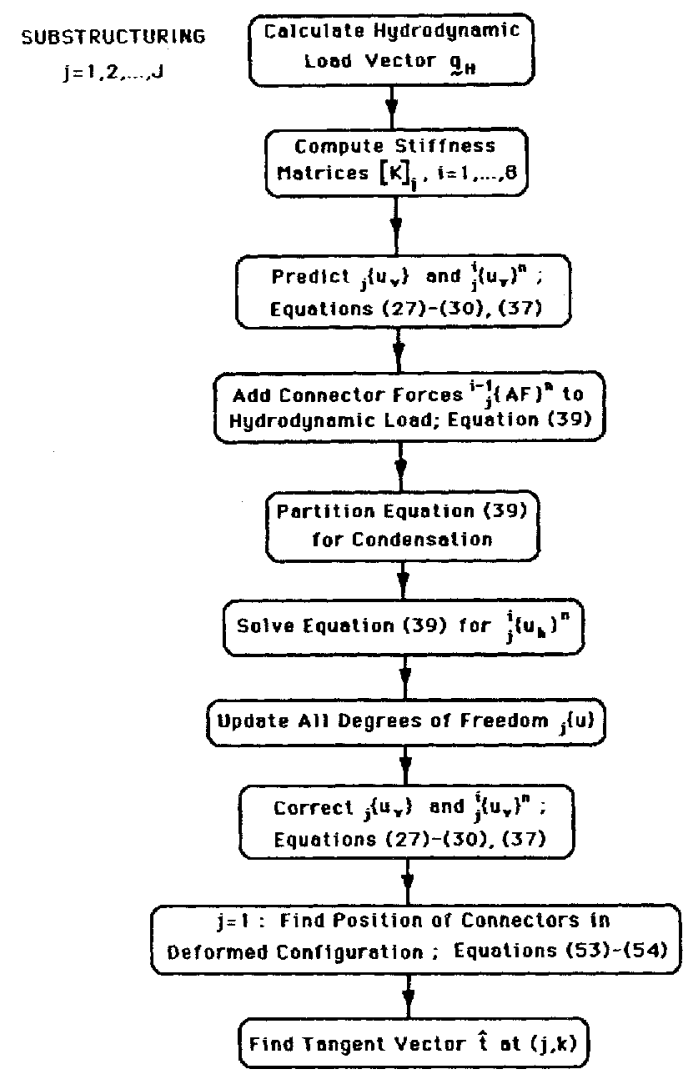

Figure 6. Solution algorithm: substructuring

should be pointed out that in equation (18) all quantities appearing in front of the integrals are considered constant for each element.

From the above weak form, matrix equation (26) can be derived by using (24) and (25),

$$
\begin{aligned}
\Delta x_{d} & =\Delta x_{d \beta} N_{\beta} \\
\bar{x}_{c} & =\bar{x}_{c \alpha} N_{\alpha}, \quad \alpha, \beta=1, \ldots, 4, \quad c, d=1,2,3
\end{aligned}
$$

where $N_{\alpha}, N_{\beta}$ are the usual cubic beam shape functions and $\Delta x_{d \beta}$ are the twelve degrees of freedom of the element (six for each node);

$$
\left(\sum_{l=1}^{8}\left[K_{l}\right]\right)_{j}\{u\}={ }_{j}\{F\}+{ }_{j}\{A F\}, j=1,2, \ldots, J
$$

where ${ }_{j}\{u\}$ is the deformation vector due to the external force vector ${ }_{j}\{F\}$ and the force vector ${ }_{j}\{A F\}$ due to the $K$ connectors. The latter includes connector induced forces and moments ${ }_{j} \mathbf{A F}^{k}$ and ${ }_{j} \mathbf{A M}{ }^{k}$. The $l$ th matrix is derived from the $l$ th integral on the left hand side of equation (18). Suffice to say that

${ }_{j}\left[K_{1}\right]$ is symmetric, represents bending stiffness and is proportional to $B$; ${ }_{j}\left[K_{2}\right]$ is symmetric, represents geometric stiffness and is proportional to $\left(T_{e}-B \kappa^{2}\right)$; 
${ }_{j}\left[K_{3}\right]$ is non-symmetric, represents the effect of incremental variation of effective tension $T_{\mathrm{e}}$; ${ }_{j}\left[K_{4}\right]$ is non-symmetric, represents the effect of incremental variation of $B \kappa^{2}$; ${ }_{j}\left[K_{5}\right]$ and ${ }_{j}\left[K_{6}\right]$ are skew-symmetric and proportional to torsional moment $H$; ${ }_{j}\left[K_{7}\right]$ is skew-symmetric and is due to distributed moment; ${ }_{j}\left[K_{8}\right]$ is skew-symmetric and is due to concentrated moment.

All stiffness matrices and, in general, the hydrodynamic load are deformation dependent. Iterations are performed in each increment until convergence of degrees of freedom is achieved. An iterative procedure with predictor and corrector phases is used in each increment. In the predictor phase $x_{3}, x_{3}^{\prime}, \Delta x_{3}, \Delta x_{3}^{\prime}$ are computed using the following kinematic relations:

$$
\begin{aligned}
x_{3}= & x_{3}(0)+\int_{0}^{s_{1}} x_{3}^{\prime} \mathrm{d} s_{1} \\
x_{3}^{\prime}= & \left(1-x_{2}^{\prime 2}-x_{1}^{\prime 2}\right)^{1 / 2}-\frac{1}{1+\varepsilon_{t}} \\
\Delta x_{3}= & \int_{0}^{s_{1}} \Delta x_{3}^{\prime} \mathrm{d} s_{1} \\
\Delta x_{3}^{\prime}= & {\left[1+\frac{F_{3}}{E A\left(1+\varepsilon_{t}\right)^{2}}\right]\left[-\frac{x_{2}^{\prime} \Delta x_{2}^{\prime}+x_{1}^{\prime} \Delta x_{1}^{\prime}}{x_{3}^{\prime}+\frac{1}{1+\varepsilon_{\mathrm{t}}}+\frac{1}{E A\left(1+\varepsilon_{t}\right)^{2}+F_{3}}}\right.} \\
& \left.\times\left[\Delta F_{1} x_{1}^{\prime}+\Delta F_{2} x_{2}^{\prime}+\Delta F_{3}\left(x_{3}^{\prime}+\frac{1}{1+\varepsilon_{\mathrm{r}}}\right)+F_{1} \Delta x_{1}^{\prime}+F_{2} \Delta x_{2}^{\prime}-\Delta x_{3} g\left(\rho_{\mathrm{m}} A_{\mathrm{i}}-\rho_{\mathrm{w}} A_{\mathrm{o}}\right)\right]\right]
\end{aligned}
$$

where equation (28) is derived from (10), and equation (30) is derived by elimination of $\Delta \varepsilon_{\mathrm{r}}$ and $\Delta T_{\mathrm{e}}$ from the incremental form of (28) and

$$
\begin{aligned}
& \Delta T_{\mathrm{c}}=\Delta F_{1} x_{1}^{\prime}+\Delta F_{2} x_{2}^{\prime}+\Delta F_{3}\left(x_{3}^{\prime}+\frac{1}{1+\varepsilon_{t}}\right)+F_{1} \Delta x_{1}^{\prime}+F_{2} \Delta x_{2}^{\prime}+F_{3} \Delta x_{3}^{\prime}-F_{3} \frac{\Delta \varepsilon_{t}}{\left(1+\varepsilon_{t}\right)^{2}} \\
& \Delta T_{\mathrm{e}}=E A \Delta \varepsilon_{t}-\Delta x_{3} g\left(\rho_{\mathrm{w}} A_{0}-\rho_{\mathrm{m}} A_{j}\right)
\end{aligned}
$$

which are the incremental counterparts of equation $(8)$ and

$$
T_{\mathrm{e}}=\mathbf{F} \cdot \hat{t}
$$

In the prediction phase $x_{1}, x_{1}^{\prime}, \Delta x_{1}, \Delta x_{1}^{\prime}, x_{2}, x_{2}^{\prime}, \Delta x_{2}, \Delta x_{2}^{\prime}$ are computed using (26). Durng the correction phase $x_{3}, x_{3}^{\prime}, \Delta x_{3}, \Delta x_{3}^{\prime}$ are recomputed using equations (27) (30), and all stiffness matrices, the equivalent nodal forces, the boundary conditions and the lengths of the elements are corrected. Further, $x_{1}, x_{1}^{\prime}, \Delta x_{1}, \Delta x_{1}^{\prime}, x_{2}, x_{2}^{\prime}, \Delta x_{2}, \Delta x_{2}^{\prime}$ are recomputed using equation (26).

\subsection{Substructuring condensation algorithm}

In each iteration substructuring and condensation is performed and the problems of the component-risers and connectors are solved. In order to explain the algorithm the following symbols are defined:

$p=1,2, \ldots, P, \quad p$ is the node number in the finite element discretization and $P$ is the number of nodes in each riser; 
$n=1,2, \ldots, N, \quad n$ is the increment number and $N$ is the number of increments; the incremental operator $\Delta$ appearing in the incremental formulation of the previous section is replaced by $n$ in the following notation;

$i=1,2, \ldots, I, \quad i$ is the iteration number and $I$ is the number of iterations required for convergence in each increment;

${ }_{c}^{a}[]_{d,}^{b}, \underset{c}{a}\{\}_{d}^{b}$ at the locations of indices $a, b, c, d$ around a matrix or vector symbol, the iteration number $i$, the increment number $n$, the riser number $j$ and the type of degree of freedom (constrained by a connector or not) are indicated, respectively.

For the $j$ th riser, equation of equilibrium (26) in the $i$ th iteration of the $n$th increment takes the form

$$
{ }_{j}^{i-1}[K]_{j}^{n i}\{u\}^{n}={ }_{j}^{i}\{F\}^{n}+{ }^{i-1}\{A F\}^{n}
$$

where $[K]$ is the sum of the eight stiffness matrices appearing in equation (18). The riser bundle is substructured into $j$ risers and $K$ connectors. Each riser substructure is analysed using equation (34) and each connector substructure by using rigid body equilibrium equations.

Condensation of certain degrees of freedom of the $j$ th riser-substructure is achieved in the following way. First equation (34) is partitioned as follows:

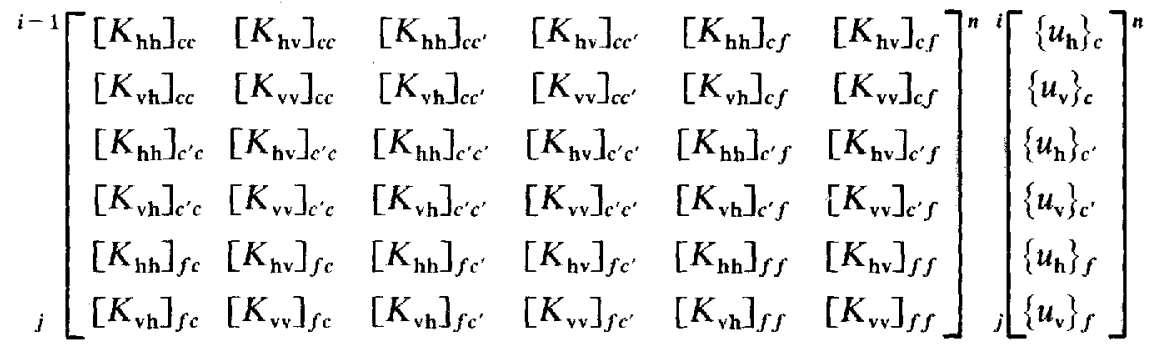

$$
\begin{aligned}
& =\left[\begin{array}{l}
\left\{F_{\mathrm{h}}\right\}_{c} \\
\left\{F_{\mathrm{v}}\right\}_{c} \\
\left\{F_{\mathrm{h}}\right\}_{c^{\prime}} \\
\left\{F_{\mathrm{v}}\right\}_{c^{\prime}} \\
\left\{F_{\mathrm{h}}\right\}_{f} \\
\left\{F_{\mathrm{v}}\right\}_{f}
\end{array}\right]^{i-1}\left[\begin{array}{l}
\left\{A F_{\mathrm{h}}\right\}_{c} \\
\left\{A F_{\mathrm{v}}\right\}_{c} \\
\left\{A F_{\mathrm{b}}\right\}_{c^{\prime}} \\
\left\{A F_{\mathrm{v}}\right\}_{\mathrm{c}^{\prime}} \\
\left\{A F_{\mathrm{h}}\right\}_{f} \\
\left\{A F_{\mathrm{v}}\right\}_{f}
\end{array}\right]^{n}
\end{aligned}
$$

where indices $c, c^{\prime}, f, \mathrm{~h}, \mathrm{v}$ indicate

c: displacements at nodes with connectors

$c^{\prime}$ : derivatives of displacements at nodes with connectors

$f: \quad$ displacements or derivatives at free nodes (no connectors)

$h$, v: horizontal and vertical degrees of freedom.

where

$$
{ }_{j}\left\{\begin{array}{c}
\left\{A F_{\mathrm{h}}\right\}_{c} \\
-\cdots \\
\left\{A F_{\mathrm{v}}\right\}_{c}
\end{array}\right\}^{n} \neq\{0\}, \quad\left\{\begin{array}{c}
\left\{A F_{\mathrm{h}}\right\}_{c^{\prime}} \\
--- \\
\left\{A F_{\mathrm{v}}\right\}_{\mathrm{c}^{\prime}}
\end{array}\right\}=\{0\} \text { for } j=2,3, \ldots, J
$$


For riser \#1, owing to assumption (vii) the last equation does not hold. Further,

$$
\left\{\begin{array}{c}
\left\{A F_{\mathrm{h}}\right\}_{f} \\
----- \\
\left\{A F_{\mathrm{v}}\right\}_{f}
\end{array}\right\}^{n}=\{0\} \quad \text { for } \quad j=2,3, \ldots, J
$$

For each connector $(k=1, \ldots, K)$ and each riser with the exception of the central one $(j$ $=2, \ldots, J)$, at each increment $(n=1, \ldots, N)$ the connector force is normal to the tangent vector of each component riser. Thus, equation (17)- the non-friction in the guide arm funnels constraint--yields

$$
\begin{aligned}
& { }_{j}^{i-1} \mathbf{A F}^{k, n,{ }^{i-1}} \hat{t}^{k, n}=0 \Rightarrow \\
& { }_{j}^{i-1} A F_{1}^{k, n, i-\frac{1}{j}} t_{1}^{k, n}+{ }^{i-1} A F_{2}^{k, n, i-1}{ }_{j}^{k, n}+{ }_{2}^{i-1} A F_{3}^{k, n, i-1}{ }_{j}^{k} t_{3}^{k, n}=0 \\
& \text { for } j=2, \ldots, J
\end{aligned}
$$

Condensation of equation (35) for each component riser occurs in three steps. First the vertical degrees of freedom are decoupled and computed in each iteration using the prediction-correction scheme described by equations (27) to (33). After elimination of the vertical degrees of freedom equation (35) is reduced to

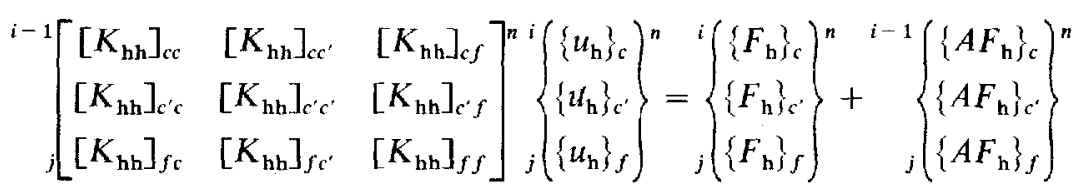

The second step of condensation takes place when advancing from iteration $i$ to iteration $i+1$. Specifically the following equation holds:

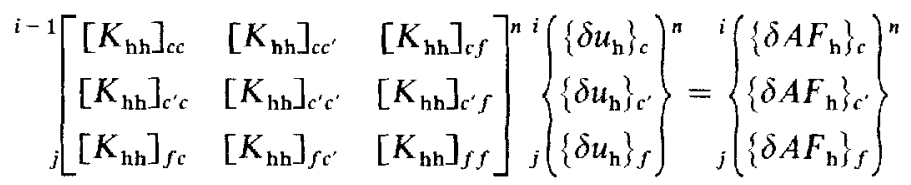

where ${ }_{j}^{i}\{\delta u\}^{n}$ indicates additional displacements due to the additional forces ${ }_{j}^{i}\{\delta A F\}^{n}$ exerted between connectors and risers at the $i$ th iteration in the $n$th increment. At the end of this $(i, n)$ iteration, ${ }_{j}^{i}\{\delta\}^{n}$ and ${ }_{j}^{i}\{\delta A F\}^{n}$ should be added to ${ }_{j}^{i}\{u\}^{n}$ and ${ }_{j}^{i}\{A F\}^{n}$ in order to update their values. Further, since

$$
{ }_{j}^{i}\left\{\delta A F_{\mathrm{h}}\right\}^{n}=\{0\}
$$

${ }_{j}^{i}\left\{\delta u_{\mathrm{h}}\right\}_{f}^{n}$ can be eliminated from equation (40). This yields

$$
\begin{aligned}
{ }_{j}^{i}\left\{\delta u_{\mathrm{h}}\right\}_{f}^{n}= & -\left[{ }^{i-1}\left[K_{\mathrm{hh}}\right]_{f f}^{n}\right]^{-1 i-1}\left[K_{\mathrm{hh}}\right]_{f c}^{n}{ }_{j}^{i}\left\{\delta u_{\mathrm{h}}\right\}_{\mathrm{c}}^{n} \\
& -\left[{ }^{i-1}\left[K_{\mathrm{hh}}\right]_{f f}^{n}\right]^{-1 i-1}\left[K_{\mathrm{hh}}\right]_{f c^{\prime}}^{n}{ }_{j}^{i}\left\{\delta u_{\mathrm{h}}\right\}_{c^{\prime}}^{n}
\end{aligned}
$$

Owing to equation (36), (43) holds

$$
{ }_{j}^{i}\left\{\delta A F_{\mathrm{h}}\right\}_{c^{\prime}}^{n}=\{0\} \text { for } j=2, \ldots, J
$$

Thus, ${ }_{j}^{i}\left\{\delta u_{\mathrm{h}}\right\}_{c^{\prime}}^{n} j=2, \ldots, J$ can be eliminated from equation (40) by combining (42) and (43). This process yields

$$
{ }_{j}^{i}\left\{\delta u_{\mathrm{h}}\right\}_{c^{\prime}}^{n}=\left[{ }^{i-1}[\mathrm{P} 1]^{n}\right]^{-1 i-}{ }_{j}^{1}[\mathrm{P} 2]^{n}{ }_{j}^{i}\left\{\delta u_{\mathrm{h}}\right\}_{c}^{n} \text { for } j=2, \ldots, J
$$


where

$$
\begin{array}{r}
{ }_{j}^{i-1}[\mathrm{P} 1]^{n}={ }_{j}^{i-1}\left[K_{\mathrm{hh}}\right]_{c^{\prime} f}^{n}\left[{ }_{j}^{i-1}\left[K_{\mathrm{hh}}\right]_{f f}^{n}\right]^{-1 i-1}\left[K_{\mathrm{hh}}\right]_{f c^{\prime}}^{n}-{ }_{j}^{i-1}\left[K_{\mathrm{hb}}\right]_{c^{\prime} c^{\prime}}^{n} \\
\text { for } j=2, \ldots, J
\end{array}
$$

and

$$
\begin{aligned}
{ }_{j}^{i-1}[\mathrm{P} 2]^{n}={ }_{j}^{i-1}\left[K_{\mathrm{hh}}\right]_{c^{\prime} c^{\prime}}^{n}-{ }^{i-1}\left[K_{\mathrm{hh}}\right]_{\mathrm{c}^{\prime} f}^{n}\left[{ }^{i-1}\left[K_{\mathrm{hh}}\right]_{f f}^{n}\right]^{-1 i-1}\left[K_{\mathrm{hhl}}\right]_{f c}^{n} \\
\text { for } j=2, \ldots, J
\end{aligned}
$$

This elimination process produces

$$
{ }_{j}^{i-1}[\mathrm{P} 3]^{n}{ }_{j}^{i}\left\{\delta u_{\mathrm{h}}\right\}_{\mathrm{c}}^{n}={ }_{j}^{i}\left\{\delta A F_{\mathrm{h}}\right\}_{c}^{n} \text { for } j=2, \ldots, J
$$

where

$$
\begin{aligned}
&{ }_{j}^{i-1}[\mathrm{P} 3]^{n=}={ }_{j}^{i-1}\left[K_{\mathrm{hh}}\right]_{c c}^{n}+{ }_{j}^{i-1}\left[K_{\mathrm{hh}}\right]_{c c^{\prime}}^{n}\left[{ }^{i-1}[\mathrm{P} 1]^{n}\right]^{-1 i-1}[\mathrm{P} 2]^{n} \\
&-{ }_{j}^{i-1}\left[K_{\mathrm{hh}}\right]_{c f}^{n}\left[{ }^{i-1}\left[K_{\mathrm{hh}}\right]_{j f}^{n}\right]^{-1 i-1}{ }_{j}\left[K_{\mathrm{hh}}\right]_{f c}^{n} \\
&-{ }_{j}^{i-1}\left[K_{\mathrm{hh}}\right]_{c f}^{n}\left[{ }_{j}^{i-1}\left[K_{\mathrm{hh}}\right]_{f f}^{n}\right]^{-1 i-1}{ }_{j}\left[K_{\mathrm{hh}}\right]_{f f^{\prime}}^{n}\left[{ }^{i-1}[\mathrm{P} 1]^{n}\right]^{-1}{ }_{j}^{i-1}[\mathrm{P} 2]^{n} \\
& \text { for } \quad j=2, \ldots, J
\end{aligned}
$$

To eliminate ${ }_{j=1}^{i}\left\{\delta u_{\mathrm{h}}\right\}_{\mathrm{c}^{\prime}}^{n}$ from equation $(40)$ the following two-phase scheme is used. The counterparts of equations (44) and (47) are

$$
\begin{aligned}
& i\left\{\delta u_{\mathrm{h}}\right\}_{c^{\prime}}^{n}=\left[{ }_{1}^{i-1}[\mathrm{P} 1]^{n}\right]^{-1 i-1}[\mathrm{P} 2]^{n i-1}{ }_{1}\left\{\delta u_{\mathrm{h}}\right\}_{c}^{n}-\left[{ }_{1}^{i-1}[\mathrm{P} 1]^{n}\right]^{-1 i-1}{ }_{1}\left\{\delta A F_{\mathrm{h}}\right\}_{c^{\prime}}^{n} \\
&{ }_{1}{ }_{1}[\mathrm{P} 3]^{n i-1}\left\{\delta u_{\mathrm{h}}\right\}_{c}^{n}={ }_{1}^{i}\left\{\delta A F_{\mathrm{h}}\right\}_{\mathrm{c}}^{n}+{ }^{i-1}{ }_{1}\left\{\delta A F_{\mathrm{h}}\right\}_{\mathrm{c}^{\prime}}^{n}
\end{aligned}
$$

where

$$
\begin{aligned}
{ }^{i-1} 1\left\{\delta A F_{\mathrm{h}}\right\}_{c c^{\prime}}^{n}= & { }_{1}^{i-1}\left[K_{\mathrm{hh}}\right]_{c c^{\prime}}^{n}\left[i_{1}^{i-1}[\mathrm{P} 1]^{n}\right]^{-1 i-1}{ }_{1}\left\{\delta A F_{\mathrm{h}}\right\}_{c^{\prime}}^{n} \\
& -{ }^{i-1}\left[K_{\mathrm{hh}}\right]_{c f}^{n}\left[{ }^{i-1}\left[K_{\mathrm{hh}}\right]_{f f}^{n}\right]^{-1 i-1}{ }_{1}\left[K_{\mathrm{hb}}\right]_{f c^{\prime}}^{n}\left[{ }_{1}^{i-1}[\mathrm{P} 1]^{n}\right]^{-1 i-1}{ }_{1}^{1}\left\{\delta A F_{\mathrm{h}}\right\}_{c^{\prime}}^{n}
\end{aligned}
$$

In the first phase, the last terms in equations (49) and (50) are evaluated from the previous iteration. These terms are actually additional terms that do not appear in the counterpart equations (44) and (47).

In the second phase we compute $\left.{ }_{j}^{i} \delta \delta A F_{\mathrm{h}}\right\}_{c}^{n}$ for $j=1, \ldots, J$ and ${ }_{1}^{i}\left\{\delta A F_{\mathrm{h}}\right\}_{c^{\prime}}^{n}$ using the geometry of the $K$ connectors.

$$
\begin{aligned}
\sum_{m=1}^{n-1} I(m)\left\{u_{\mathrm{h}}\right\}_{c}^{m}+ & { }_{j}^{i}\left\{u_{\mathrm{h}}\right\}_{c}^{n}+{ }_{j}^{i}\left\{\delta u_{\mathrm{h}}\right\}_{c}^{n}-\sum_{m=1}^{n-1} I(m)\left\{u_{\mathrm{h}}\right\}_{\mathrm{c}}^{m}-{ }_{1}\left\{u_{\mathrm{h}}\right\}_{c}^{n} \\
- & { }_{1}^{i}\left\{\delta u_{\mathrm{h}}\right\}_{c}^{n}={ }^{n}\left\{d_{1 j}\right\}^{n} \text { for } j=2, \ldots, J
\end{aligned}
$$

where summations add all incremental displacements up to increment $n-1, I(n)$ indicates total number of iterations required in increment $n$ and ${ }^{i}\left\{d_{1 j}\right\}^{\mathrm{n}}$ is the vector of the horizontal components of the distances between risers 1 and $j$ in the $K$ connectors. For the $k$ th connector ${ }^{i} \mathbf{d}_{1 j}^{k, n}$ is computed as follows:

$$
\mathbf{d}_{1 j}^{k, n}={ }^{i}\left[{ }_{k} T R\right]^{n} \mathbf{o}_{1 j}^{k}
$$

where

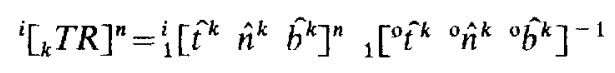

superscript ${ }^{\circ}$ indicates initial riser configuration, ${ }^{i}\left[{ }_{k} T R\right]^{n}$ is a transformation matrix defined by 
equation (54), and $(\hat{t}, \hat{n}, \hat{b})$ are the unit local principle vectors. Derivation of equation (54) is based on assumption (vii). Substituting ${ }_{1}^{i}\left\{\delta u_{\mathrm{h}}\right\}_{c}^{n}$ from equation (50) and ${ }_{j}^{i}\left\{\delta u_{\mathrm{h}}\right\}_{c}^{n}$ for $j=2, \ldots, J$ from equation (47) in equation (52) yields

$$
\begin{aligned}
&{ }_{j}^{i}\left\{\delta A F_{\mathrm{h}}\right\}_{c}^{n}={ }_{j}^{i-1}[\mathrm{P} 3]^{n}\left[i\left\{d_{1 j}\right\}^{n}-\sum_{m=1}^{n-1} I(m)\left\{u_{\mathrm{h}}\right\}_{c}^{m}-{ }_{j}^{i}\left\{u_{\mathrm{h}}\right\}_{c}^{n}+\sum_{m=1}^{n-1} I(m)\left\{u_{\mathrm{h}}\right\}_{\mathrm{c}}^{m}\right. \\
&\left.+{ }_{1}^{i}\left\{u_{\mathrm{h}}\right\}_{c}^{n}+\left[{ }_{1}^{i-1}[\mathrm{P} 3]^{n}\right]^{-1}{ }_{1}^{i}\left\{\delta A F_{\mathrm{h}}\right\}_{c}^{n}+\left[{ }_{1}^{i-1}[\mathrm{P} 3]^{n}\right]^{-1 i-1}\left\{\delta A F_{\mathrm{h}}\right\}_{c c^{\prime}}^{n}\right] \\
& \text { for } j=2, \ldots, J
\end{aligned}
$$

The only unknown quantity in the right hand side of equation (55) is ${ }_{1}^{i}\left\{\delta A F_{\mathrm{h}}\right\}_{c}^{n}$. To determine it the equation of equilibrium of horizontal forces for each one of the $K$ connectors is used. Thus

$$
\sum_{j=1}^{j}{ }_{j}^{i}\left\{\delta A F_{\mathrm{h}}\right\}_{\mathrm{c}}^{n}=0
$$

Combining equations (55) and (56) produces

$$
\begin{aligned}
i\left\{\delta A F_{\mathrm{h}}\right\}_{\mathrm{c}}^{n}= & {\left[[I]+\left(\sum_{j=2}^{J}{ }^{i-1}[\mathrm{P} 3]^{n}\right)\left[^{i-1}[\mathrm{P} 3]^{n}\right]^{-1}\right]^{-1} \cdot \sum_{j=2}^{J}\left\{{ } _ { j } ^ { i - 1 } [ \mathrm { P } 3 ] ^ { n } \left[-{ }^{i}\left\{d_{1 j}\right\}^{n}\right.\right.} \\
& +\sum_{m=1}^{n-1}\left[(m)\left\{u_{\mathrm{h}}\right\}_{c}^{m}+{ }_{j}^{i}\{u\}_{c}^{n}-\sum_{m=1}^{n-1} I(m)\left\{u_{\mathrm{h}}\right\}_{c}^{m}-{ }_{1}^{i}\left\{u_{\mathrm{h}}\right\}_{c}^{n}\right. \\
& \left.\left.-\left[{ }_{1}^{i-1}[\mathrm{P} 3]^{n}\right]^{-1}{ }^{-1}{ }_{1}\left\{\delta A F_{\mathrm{h}}\right\}_{c c^{\prime}}^{n}\right]\right\}
\end{aligned}
$$

Substituting ${ }_{1}^{i}\left\{\delta A F_{\mathrm{h}}\right\}_{c}^{n}$ from the last equation into equation (55) yields the horizontal connector forces ${ }_{j}^{i}\left\{\delta A F_{\mathrm{h}}\right\}_{c}^{n}$ for $j=2, \ldots, J$. To produce the vertical forces equation (58) is used,

$$
{ }_{j}^{i}\left\{\delta A F_{v}\right\}_{c}^{n}=[T]_{j}^{i}\left[T_{t}\right]_{j}^{n}{ }_{j}^{i}\left\{\delta A F_{\mathrm{h}}\right\}_{c}^{n} \text { for } j=2, \ldots, J
$$

where transformation matrices $[T]$ and ${ }_{j}^{i}\left[T_{t}\right]^{n}$ express in matrix form the non-friction constraints (17). Equilibrium of vertical forces for each one of the $K$ connectors gives

$$
{ }_{1}^{i}\left\{\delta A F_{\mathrm{v}}\right\}_{c}^{n}=-\sum_{j=2}^{J}{ }_{j}^{i}\left\{\delta A F_{\mathrm{v}}\right\}_{c}^{n}
$$

Finally, equilibrium of moments at the $k$ th connector yields the moment exerted on the central riser as the following vector cross product:

$$
{ }_{1}^{i}\left({ }_{k} \delta A F\right)_{c^{\prime}}^{n}=\sum_{j=2}^{J}{ }^{i}\left(\mathbf{d}_{1 j}^{k}\right)^{n} \times{ }_{j}^{i}\{k \delta A F\}_{\mathfrak{r}}^{n}
$$

This constitutes the end of iteration $i$.

\section{NUMERICAL APPLICATIONS}

The algorithm developed in the previous section has been implemented in program PRODRIS.NL (PRODuction RISer, NonLinear analysis). One of the major difficulties encountered in developing algorithms for non-linear analysis is computer code verification. Several simple three-dimensional verification cases have been studied to test substructuring and condensation in PRODRIS.NL. These are presented in Subsection 4.1. The incremental finite element algorithm has been tested by comparison with program STARI-3D for three-dimensional analysis 
of a single riser. ${ }^{6}$ Comparisons, for a $100 \mathrm{~m}$ production riser using PRODRIS. ${ }^{5}$ for linear analysis and PRODRIS.NL for non-linear analyses with deformation independent and dependent hydrodynamic loads, are performed in Subsection 4.3 and provide further indication regarding the program's accuracy. Two practical applications for a bundle with seven component-risers and water depth of 100 and $600 \mathrm{~m}$ are solved in Subsection 4.2 .

\subsection{Simple verification cases}

Figure 7 shows eight positional combinations of two identical risers. The riser located at the origin of co-ordinates is the central one on which all connectors are welded. The second riser is a peripheral one which passes through the connector funnels. In all eight cases the two componentrisers are loaded uniformly by loads equal in magnitude and opposite in direction as indicated by the arrows in Figure 7. The following intuitively obvious facts have been verified.

(i) Force and moment equilibria of connectors hold in all cases. Riser deflection at connectors was checked and found to be compatible with geometric constraints.

(ii) In case \# 1, owing to structural asymmetry, the induced torque results in riser displacement in the positive $y$-direction.

(iii) Rotation of the production riser and its loading by $180^{\circ}$ results in sign change of the horizontal displacement degrees of freedom and no change in torque. This is verified by comparing pairs of cases (\#1, \#8), (\#2, \#4), (\#5, \#6), (\#3, \#7).

(iv) The following pairs of cases are symmetric with respect to the $x$-axis: $(\# 1, \# 2),(\# 3, \# 5)$, $(\# 6, \# 7),(\# 4, \# 8)$. The horizontal displacement degrees of freedom in the $x$-direction are identical, in the $y$-direction are opposite in sign, and the induced torque also changes sign.

(v) Symmetry with respect to the $y$-axis as in pairs $(\# 1, \# 4),(\# 2, \# 8),(\# 3$, \#6), (\#5, \#7) results in change of sign in the $x$-direction, horizontal displacement and induced torque, while it has no effect on the $y$-direction horizontal displacement.

Figure 8 shows two cases of a three-component production riser. The two peripheral risers are subject to a uniform load half in magnitude of that applied on the central riser. These cases result in zero torque and zero $y$-direction horizontal displacement while the $x$-direction horizontal displacement changes sign as expected.

\subsection{Numerical applications}

All component-risers in the numerical applications in this and the next subsection are identical and their properties are listed in Table I. A $100 \mathrm{~m}$ and a $600 \mathrm{~m}$ production riser are used in the applications. They are composed of a central riser and six peripheral risers placed around the central one in a hexagonal arrangement with distance between centres of any two adjacent component-risers equal to $3 D_{\mathrm{H}}$. They are subject to a tidal current of surface velocity $V_{\mathrm{s}}$ $=1.0 \mathrm{~m} / \mathrm{sec}$ in the negative $y$-direction and a regular linear wave of $10 \mathrm{sec}$ period and $8 \mathrm{~m}$ height propagating in the negative $x$-direction. The values of the drag coefficient $C_{\mathrm{D} 1}$ are given in Reference 14. For a fully exposed riser, like $\# 2$ and $\# 3$ in Figure $2, C_{D}=0 \cdot 9$. For a fully shielded riser, that is a riser in the wake of another, like risers \#1 and \#6, $C_{D}=-0 \cdot 2$. The rest of the component-risers in Figure 2 are occasionally exposed or shielded, depending on the direction of the resultant hydrodynamic velocity.

In the first application a $100 \mathrm{~m}$ riser is analysed by PRODRIS.NL and the results are shown in Figure 9 for the lateral displacement in $x$ and $y$, and in Figure 10 for the maximum equivalent 

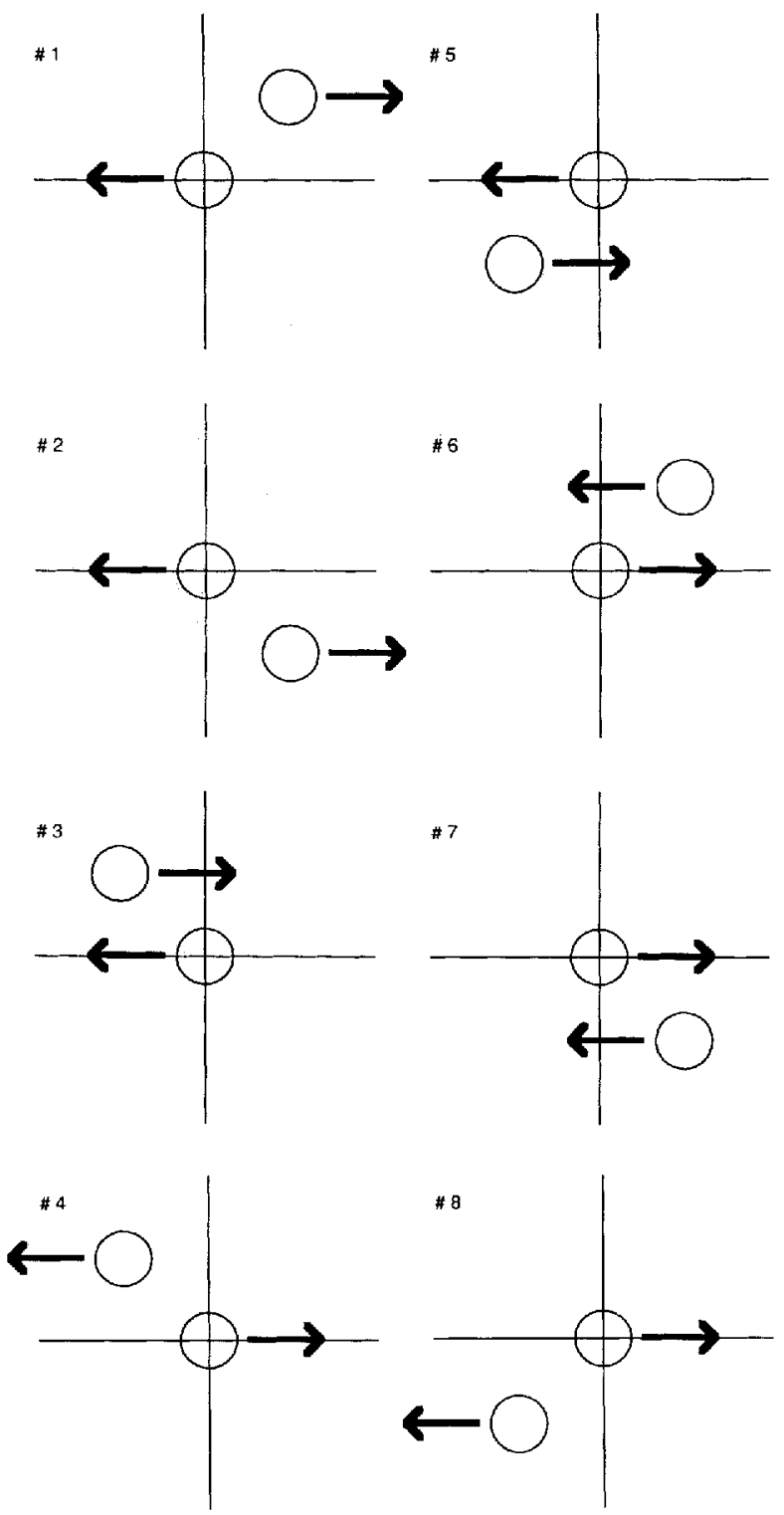

Figure 7. Simple verification case: two-component riser bundle

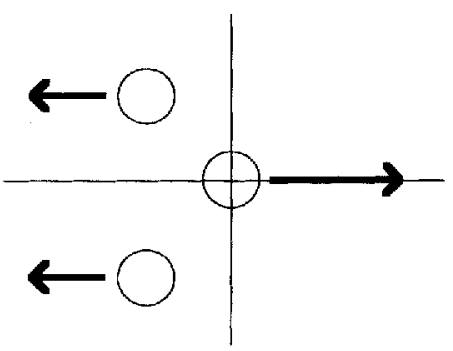

Figure 8. Simple verification case: three-component riser bundle 
Table I. Properties of riser used in numerical applications

\begin{tabular}{ll}
\hline Property & Value \\
\hline External diameter, $D_{\mathrm{o}}$ & $0.61 \mathrm{~m}$ \\
Internal diameter, $D_{\mathrm{i}}$ & $0.57 \mathrm{~m}$ \\
Density of steel pipes, $\rho_{\mathrm{st}}$ & $8,000 \mathrm{~kg} / \mathrm{m}^{3}$ \\
Density of water, $\rho_{\mathrm{w}}$ & $1,025 \mathrm{~kg} / \mathrm{m}^{3}$ \\
Density of drilling internal fluid, $\rho_{\mathrm{i}}$ & $1,250 \mathrm{~kg} / \mathrm{m}^{3}$ \\
Length (in static application), $L$ & $600 \mathrm{~m}, 100 \mathrm{~m}$ \\
Buoyancy module diameter (in static application), $D_{\mathrm{B}}$ & $0.96 \mathrm{~m}$ \\
Density of buoyancy modules (in static application), $\rho_{\mathrm{B}}$ & $350 \mathrm{~kg} / \mathrm{m}^{3}$ \\
\hline
\end{tabular}

TTR=1.5, TIDAL CURRENT: $V_{s}=1.0 \mathrm{~m} / \mathrm{sec}$, WAVE: $T=10 \mathrm{sec} H=8 \mathrm{~m}$

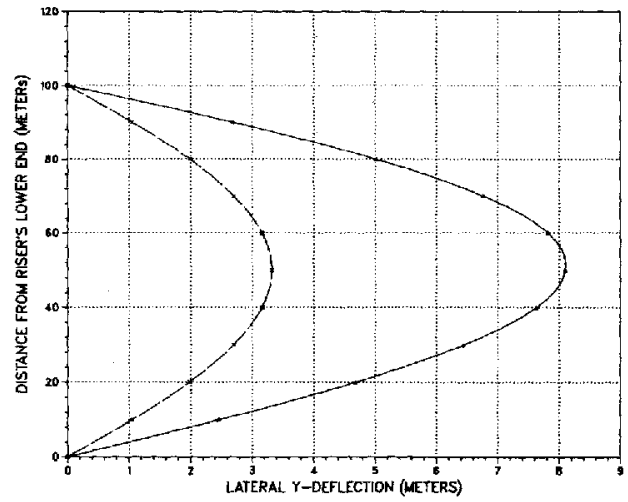

TTR=1.5, TDAL CURRENT: Vs $=1.0 \mathrm{~m} / \mathrm{sec}$, WAVE: $T=10 \mathrm{sec} H=8 \mathrm{~m}$

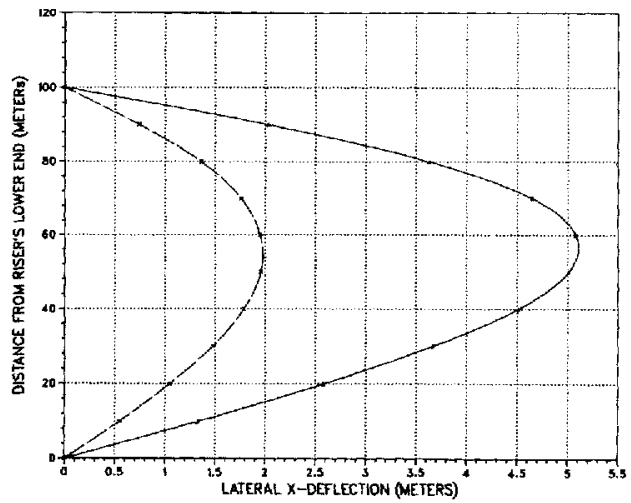

Figure 9. Displacement of $100 \mathrm{~m}$ single riser and $100 \mathrm{~m}$ seven-component riser bundle 
$\Pi R=1.5$, TOAL CURRENT: $V_{s}=1.0 \mathrm{~m} / \mathrm{sec}$, WAVE: $T=10 \mathrm{sec} H=8 \mathrm{~m}$
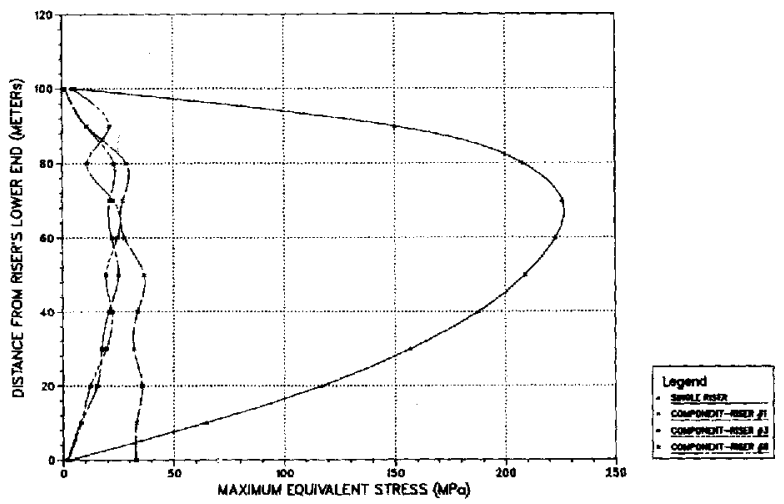

Figure 10. Maximum equivalent stress of $100 \mathrm{~m}$ single riser and components $\# 1, \# 3$ and \#6 of $100 \mathrm{~m}$ seven-component riser bundle

TTR=2.0, TIDAL CURRENT: Vs=1.0 m/sec, WAVE: $T=10 \mathrm{sec} H=8 \mathrm{~m}$

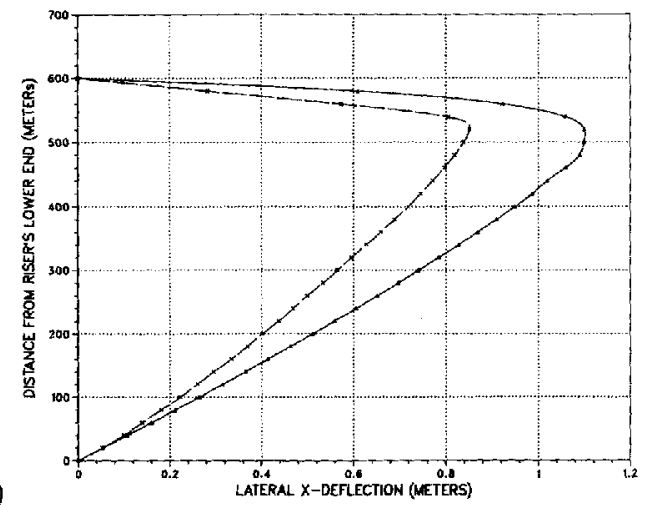

(a)

TTR=2.0, IIDAL CURRENT: $V s=1.0 \mathrm{~m} / \mathrm{sec}$, WAVE: $T=10 \mathrm{sec} H=8 \mathrm{~m}$

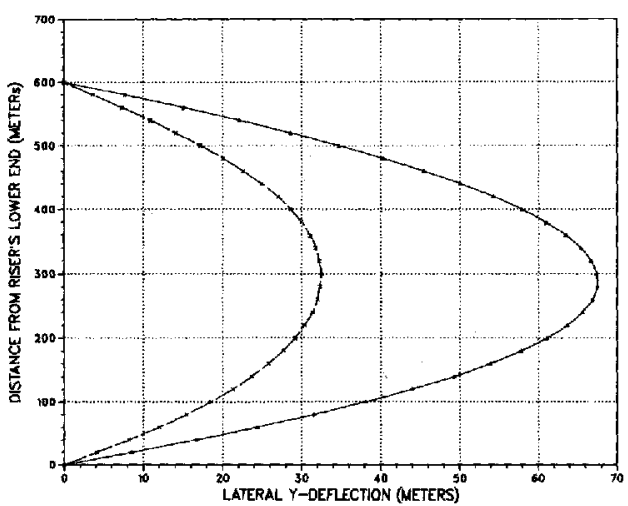

(b)

Figure 11. Displacement of $600 \mathrm{~m}$ single riser and $600 \mathrm{~m}$ seven-component riser bundle 
stress computed by the von Mises formula

$$
2 \sigma_{\mathrm{e}}^{2}=\left(\sigma_{x}-\sigma_{y}\right)^{2}+\left(\sigma_{y}-\sigma_{z}\right)^{2}+\left(\sigma_{z}-\sigma_{x}\right)^{2}+6\left(\tau_{x y}^{2}+\tau_{y z}^{2}+\tau_{z x}^{2}\right)
$$

where $\sigma_{x}, \sigma_{y}, \sigma_{z}$ are the normal and $\tau_{x y}, \tau_{y z}, \tau_{x z}$ the shear stresses in a local orthonormal system of co-ordinates. In Figures 9 and 10 results for a single riser are also plotted for comparison. In this case the drag coefficient is $C_{\mathrm{D}}=1-0$. Results differ significantly between the production and the single riser because of the significant load reduction per component-riser in the former. The shape of the maximum equivalent stress profile in Figure 10 is different from that of a single riser because of the presence of the connectors and the torque in component-riser \#1.

In the second application a $600 \mathrm{~m}$ riser is analysed by PRODRIS.NL and the results are shown in Figures 11 and 12. The maximum $x$-horizontal deflection is near the riser top where most of the wave action is concentrated. The shape of the maximum equivalent stress shows peaks at connectors. The maximum stress is located near the bottom of the central riser owing to torque. Even though the hydrodynamic load on the production riser is significantly reduced compared to that of the single riser the maximum stress in the production riser is much higher owing to torque.

Comparing the computational time needed in the above two applications we note the following. In an Apollo Domain 3500 computer, $556 \mathrm{sec}$ of CPU time were needed for the $100 \mathrm{~m}$ riser for eight incremental steps and a 10 finite element 399 degree of freedom model with three connectors. $21,991 \mathrm{sec}$ were needed for the $600 \mathrm{~m}$ riser for 20 incremental steps and a 30 finite element 1267 degree of freedom model with 10 connectors.

\subsection{Comparison between linear and non-linear models}

In two-dimensional deformation it is possible to compare results of linear and non-linear analyses. Specifically for the $100 \mathrm{~m}$ production riser subject to a planar tidal current three different analyses are compared: linear performed by PRODRIS.L $L^{5}$, non-linear with deformation independent hydrodynamic load and non-linear with deformation dependent hydrodynamic load, the last two performed by PRODRIS. NL. Two different values for the surface current velocity are used. For $V_{\mathrm{s}}=1.0 \mathrm{~m} / \mathrm{sec}$ and $V_{\mathrm{s}}=2.0 \mathrm{~m} / \mathrm{sec}$ results are shown in Tables II and III respectively. In the former case the hydrodynamic load is small and the resulting riser deformation is within the range

TTR=2.0, TDAL CURRENT: Vs=1.0 m/sec, WAVE: $T=10 \mathrm{sec} H=8 \mathrm{~m}$
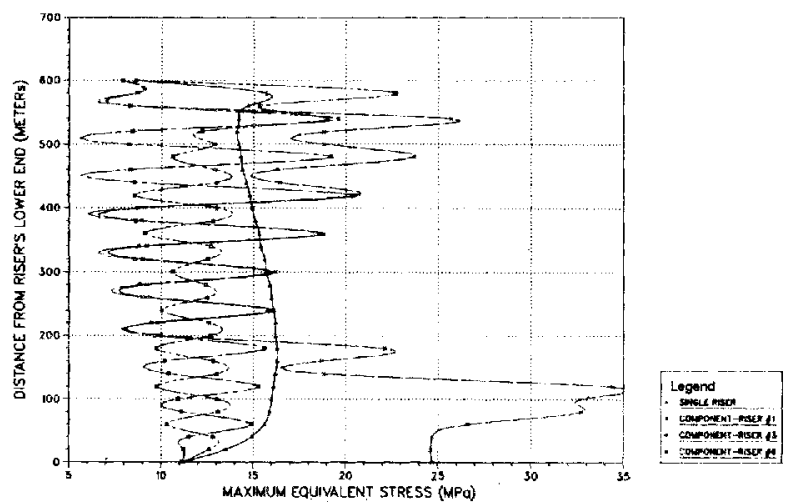

Figure 12. Maximum equivalent stress of $600 \mathrm{~m}$ single riser and components $\# 1$, \#3 and \#6 of $600 \mathrm{~m}$ seven-component riser bundle 
Table II. Displacement and stress comparison between two-dimensional linear, nonlinear, and non-linear with deformation dependent load analyses for a $100 \mathrm{~m}$ production riser subject to tidal current; $V_{\mathrm{s}}=1.0 \mathrm{~m} / \mathrm{sec}$

\begin{tabular}{|c|c|c|c|}
\hline & Linear & $\begin{array}{l}\text { Non-linear } \\
\text { deformation } \\
\text { independent }\end{array}$ & $\begin{array}{c}\text { Non-linear } \\
\text { deformation } \\
\text { dependent }\end{array}$ \\
\hline $\begin{array}{l}\text { Displacement } \\
\text { (m) }\end{array}$ & $\begin{array}{l}0 \cdot 0 \\
1 \cdot 052 \\
1 \cdot 987 \\
2 \cdot 703 \\
3 \cdot 158 \\
3 \cdot 316 \\
3 \cdot 144 \\
2 \cdot 682 \\
1 \cdot 970 \\
1 \cdot 040 \\
0.0\end{array}$ & $\begin{array}{l}0 \cdot 0 \\
1.040 \\
1.965 \\
2.674 \\
3.127 \\
3.284 \\
3.113 \\
2.655 \\
1.949 \\
1.029 \\
0.0\end{array}$ & $\begin{array}{l}0 \cdot 0 \\
1 \cdot 028 \\
1.943 \\
2 \cdot 644 \\
3.092 \\
3.247 \\
3.078 \\
2.626 \\
1.928 \\
1.018 \\
0.0\end{array}$ \\
\hline $\begin{array}{l}\text { Stress in shielded } \\
\text { component-risers } \\
\text { (MPa) }\end{array}$ & $\begin{array}{r}2.114 \\
7.692 \\
14.820 \\
16.452 \\
18.880 \\
22 \cdot 542 \\
18.514 \\
16.243 \\
15.784 \\
7.706 \\
1.676\end{array}$ & $\begin{array}{r}2 \cdot 006 \\
7 \cdot 590 \\
14 \cdot 695 \\
16 \cdot 322 \\
18 \cdot 780 \\
22 \cdot 481 \\
18 \cdot 395 \\
16 \cdot 077 \\
15 \cdot 617 \\
7 \cdot 642 \\
1 \cdot 173\end{array}$ & $\begin{array}{r}2.004 \\
7.518 \\
14.545 \\
16.143 \\
18.564 \\
22.213 \\
18.189 \\
15.911 \\
15.473 \\
7.577 \\
1.169\end{array}$ \\
\hline $\begin{array}{l}\text { Stress in exposed } \\
\text { component-risers } \\
\text { (MPa) }\end{array}$ & $\begin{array}{r}2 \cdot 197 \\
8 \cdot 162 \\
11 \cdot 902 \\
18 \cdot 946 \\
20 \cdot 863 \\
17 \cdot 501 \\
21 \cdot 080 \\
19 \cdot 141 \\
11 \cdot 444 \\
9 \cdot 986 \\
1.877\end{array}$ & $\begin{array}{r}2.047 \\
7.852 \\
11.363 \\
18.331 \\
20.207 \\
16.801 \\
20.383 \\
18.436 \\
10.732 \\
9.720 \\
1.561\end{array}$ & $\begin{array}{r}2.041 \\
7.736 \\
11.231 \\
18.114 \\
19.977 \\
16.635 \\
20.176 \\
18.257 \\
10.637 \\
9.207 \\
1.553\end{array}$ \\
\hline
\end{tabular}

of applicability of linear theory. Thus there is only a small difference between the three analyses. In the latter case, Table III, the hydrodynamic load is high and the riser deformation is beyond the limits of applicability of linear theory. As expected, the results of linear theory are invalid. The results of non-linear theory are significantly lower than those predicted by linear theory. Taking into consideration the deformation dependency of the hydrodynamic loads further reduces the riser's deflection and stresses.

\section{CONCLUSIONS}

A numerical algorithm has been developed to solve the problem of static non-linear threedimensional large deformation analysis of riser bundles subject to deformation dependent 
Table III. Displacement and stress comparison between two-dimensional linear, nonlinear and non-linear with deformation dependent load analyses for a $100 \mathrm{~m}$ production riser subject to tidal current; $V_{\mathrm{s}}=2.0 \mathrm{~m} / \mathrm{sec}$

\begin{tabular}{|c|c|c|c|}
\hline & Linear & $\begin{array}{l}\text { Non-linear } \\
\text { deformation } \\
\text { independent }\end{array}$ & $\begin{array}{c}\text { Non-linear } \\
\text { deformation } \\
\text { dependent }\end{array}$ \\
\hline $\begin{array}{l}\text { Displacement } \\
\text { (m) }\end{array}$ & $\begin{array}{c}0.0 \\
4 \cdot 209 \\
7.947 \\
10 \cdot 810 \\
12 \cdot 632 \\
13 \cdot 264 \\
12 \cdot 575 \\
10 \cdot 729 \\
7 \cdot 879 \\
4 \cdot 161 \\
0.0\end{array}$ & $\begin{array}{c}0.0 \\
3.876 \\
7 \cdot 347 \\
10.040 \\
11 \cdot 770 \\
12 \cdot 381 \\
11 \cdot 712 \\
9.954 \\
7.282 \\
3 \cdot 835 \\
0.0\end{array}$ & $\begin{array}{l}0.0 \\
3.472 \\
6.572 \\
8.981 \\
10.530 \\
11.081 \\
10.502 \\
8.947 \\
6.560 \\
3.460 \\
0.0\end{array}$ \\
\hline $\begin{array}{l}\text { Stress in shielded } \\
\text { component-risers } \\
\text { (MPa) }\end{array}$ & $\begin{array}{r}4.378 \\
29.755 \\
59.064 \\
65 \cdot 215 \\
74.634 \\
88.971 \\
72.515 \\
63.085 \\
60.906 \\
28.240 \\
5.527\end{array}$ & $\begin{array}{r}3 \cdot 275 \\
27 \cdot 322 \\
55 \cdot 745 \\
61 \cdot 667 \\
71 \cdot 496 \\
86.692 \\
69 \cdot 119 \\
59 \cdot 002 \\
57 \cdot 437 \\
26 \cdot 340 \\
2.656\end{array}$ & $\begin{array}{r}3 \cdot 022 \\
24 \cdot 446 \\
49 \cdot 482 \\
54 \cdot 794 \\
63 \cdot 432 \\
76 \cdot 741 \\
61 \cdot 787 \\
53 \cdot 384 \\
52 \cdot 471 \\
24 \cdot 274 \\
2 \cdot 440\end{array}$ \\
\hline $\begin{array}{l}\text { Stress in exposed } \\
\text { component-risers } \\
\text { (MPa) }\end{array}$ & $\begin{array}{r}4.992 \\
31 \cdot 676 \\
47 \cdot 255 \\
75 \cdot 219 \\
82 \cdot 578 \\
68 \cdot 787 \\
82.784 \\
74 \cdot 684 \\
43 \cdot 540 \\
37 \cdot 361 \\
6 \cdot 190\end{array}$ & $\begin{array}{r}3 \cdot 722 \\
28 \cdot 381 \\
41 \cdot 607 \\
69 \cdot 435 \\
77 \cdot 099 \\
62 \cdot 943 \\
77 \cdot 262 \\
68 \cdot 763 \\
37 \cdot 016 \\
31 \cdot 899 \\
4 \cdot 634\end{array}$ & $\begin{array}{r}3 \cdot 376 \\
24 \cdot 160 \\
35 \cdot 320 \\
58 \cdot 942 \\
65 \cdot 511 \\
53 \cdot 695 \\
66 \cdot 484 \\
59 \cdot 567 \\
32 \cdot 094 \\
28 \cdot 463 \\
4 \cdot 226\end{array}$ \\
\hline
\end{tabular}

hydrodynamic load. Substructuring and condensation have been used to decompose the bundle problem into those of component-risers and connectors. The resulting problems are of reduced size and can be solved with higher accuracy and speed. An incremental finite method has been used for space integration. The deformation dependent hydrodynamic load and all stiffness matrices are updated within each convergence iteration in each increment. This feature of the algorithm has been considered necessary owing to the high sensitivity of a riser's response to the deformation dependency of loads. Simple three-dimensional cases and comparison with linear two-dimensional analysis have been used to test and verify the algorithm developed. In static analysis of riser bundles, linear models are conservative, structural non-linearities result in stiffening and deformation reduction along with the deformation dependency of hydrodynamic loads. 
Grouping of risers in bundles has two additional effects which are important to design and construction. First, stresses are reduced owing to shielding of component-risers which fall in the wake of risers exposed to external flow. Second, connectors induce concentrated forces in all component-risers and torque in the central riser. Torque results in high stresses in the central riser while connector forces cause low stress fluctuations.

\section{ACKNOWLEDGEMENTS}

This publication has been partially sponsored by The University of Michigan/Sea Grant/Industry Consortium in Offshore Engineering under Michigan Sea Grant College Program, project numbers E/GLE-14 and R/T-23, under Grant Number NA85AA-D-SG045C from the Office of Sea Grant, National Oceanic and Atmospheric Administration (NOAA), U.S. Department of Commerce, and funds from the State of Michigan. Industry participants include the American Bureau of Shipping; Conoco, Ind,; Exxon Production Research; Friede and Goldman, Ltd; Noble, Denton \& Associates, Inc.; Shell Companies Foundation (1985-1986); and the U.S. Coast Guard. The U.S. Government is authorized to produce and distribute reprints for governmental purposes notwithstanding any copyright notation appearing hereon.

\section{APPENDIX}

\section{Nomenclature}

$$
\begin{array}{rl}
A & \text { cross section area } \\
\mathbf{A} \mathbf{F} & \text { forces exerted by connectors on risers } \\
B & \text { moments exerted by connectors on risers } \\
C_{\mathrm{D}} & \text { drag coefficient } \\
\mathbf{d} & \text { position vector of a funnel } \\
D_{\mathbf{H}} & \text { hydrodynamic diameter } \\
D_{\mathrm{i}} & \text { internal riser diameter } \\
D_{\mathbf{0}} & \text { external riser diameter } \\
E & \text { modulus of elasticity } \\
\mathbf{F}=\left(F_{1}, F_{2}, F_{3}\right) & \text { internal force vector } \\
H & \text { torsional moment } \\
H_{\mathrm{i}} & \text { z-co-ordinate of inner fluid free surface } \\
H_{\mathrm{w}} & z \text {-co-ordinate of water free surface } \\
\hat{i}, \hat{j}, \hat{k} & \text { triad of principal unit vector } \\
I(n) & \text { total number of interations performed during the } n \text {th load step } \\
J & \text { number of component risers in the riser bundle } \\
K & \text { number of connectors in the riser bundle } \\
{[K]} & \text { sum of the eight stiffness matrices appearing in equation }(18) \\
{\left[K_{l}\right]} & \text { lth component of }[K] \text { matrix } \\
l & \text { finite element length } \\
l_{1} & \text { finite element length after extension defined by equation }(23) \\
\mathbf{m} & \text { external moment per unit length } \\
N & \text { number of load increments } \\
P & \text { number of nodes in each riser } \\
\mathbf{M}=\left(M_{1}, M_{2}, M_{3}\right) & \text { internal moment vector } \\
&
\end{array}
$$




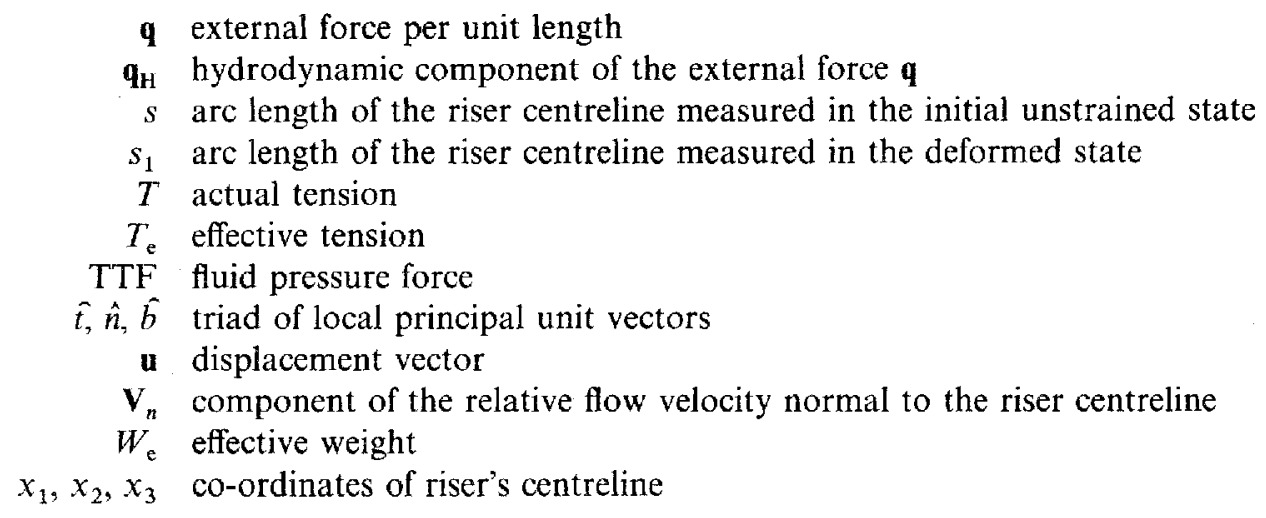

Greek symbols

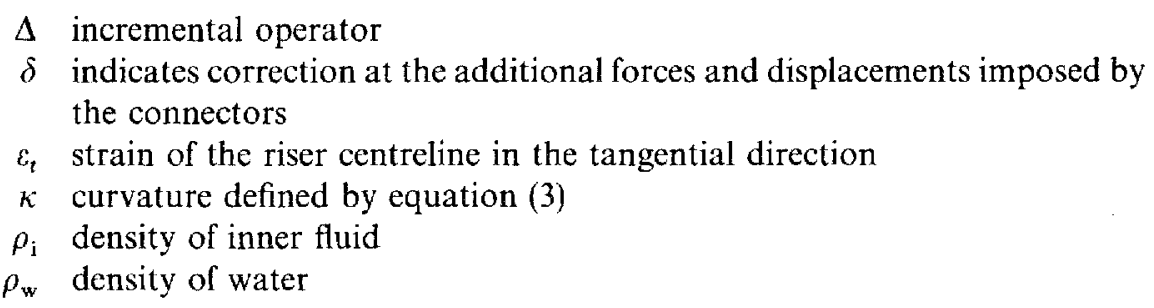

Indices

$c$ indicates displacement at nodes with connectors

$c^{\prime}$ indicates derivatives of displacements at nodes with connectors

$f$ indicates displacement or derivatives at free nodes (no connectors)

$h$ indicates horizontal degrees of freedom

$\mathrm{v}$ indicates vertical degrees of freedom

Special symbols

(') indicates the differential operator $\mathrm{d} / \mathrm{d} s_{1}$ with respect to arc length $s_{1}$ of the deformed riser centreline

${ }_{c}^{a}[]_{d}^{b}$ locations of indices $a, b, c, d$ around of a matrix of vector symbol represent the position where the iteration number $i$, the increment number $n$, the riser number $j$ and the symbols of the type of degree of freedom are placed respectively

\section{REFERENCES}

1. B. E. Bennett and G. P. Wilhelm, 'Analysis of production riser systems', Proc. Offshore Technology Conference, Houston, Texas, OTC Paper 3536, 1979, pp. 1577-1590.

2. K. Kirkland and J. Johnson, 'The production riser system for the Argyll field', Proc. Offshore Technology Conference, Houston, Texas, OTC Paper 2327, May 1975, pp. 813-817.

3. C. Pettenati-Auziere, H. Dridi, A. Birch and K. Fjell, 'Multibore dynamic riser', Proc. Offshore Technology Conference, Houston, Texas, OTC Paper 5470, Apr. 1987, pp. 4\$1-458.

4. N. Rodda, 'Production risers', Proc. Subsea International '85, Advances in Underwater Technology and offshore Engineering, Vol. 2, London, 1985, pp. 125-148.

5. N. Vlahopoulos and M. M. Bernitsas, 'Static dynamic and eigen analysis of non-integral production risers', $J$. Appl. Ocean Res., 10, No. 3 (1988).

6. M. M. Bernitsas, J. E. Kokarakis and A. Imron, 'Large deformation three-dimensional static analysis of deep water marine risers', J. Appl. Ocean Res., 7, 178-187 (1985). 
7. J. E. Kokarakis and M. M. Bernitsas, 'Effect of extensibility on large deformation three-dimensional static behavior of beams', Int. J. Mech. Struct. Machines, 15, 209-231 (1987).

8. K. H. Huebner and E. A. Thornton, The Finite Element Method for Engineers, Wiley-Interscience, New York, 1982.

9. L. Meirovitch, Computational Methods in Structural Dynamics, Sijthoff and Noordhoff, The Hague, 1980.

10. R. P. Nordgren, 'On computation of the motion of elastic rods', J. Appl. Mech., 96, $777-780$ (1974).

11. M. M. Bernitsas and J. E. Kokarakis, 'Nonlinear six-degree-of freedom dynamic model for risers, pipelines, and beams', J. Ship Res. 30, 177-185 (1986).

12. L. E. Borgman, 'Computation of the ocean-wave forces on inclined cylinders', Am. Geophys. Union, Trans., 39, No. 5 (1958).

13. S. K. Chakrabarti, W. A. Tam and A. L. Wolbert, 'Wave forces on a randomly oriented tube', Proc. Offshore Technology Conference, Houston, Texas, OTC Paper 2190, May 1975, pp. 433-447.

14. S. F. Hoerner (ed.), Fluid-Dynamic Drag, 1964.

15. Z. Demirbilek and T. Halvorsen, 'Hydrodynamic forces on multitube production risers exposed to currents and waves', J. Energy Resources Technol., 107, 226-234 (1985).

16. T. Overvik and G. Moe, 'Added mass and in-line steady drag coefficient of multiple risers', J. Energy Resources Technol., 107, 2-11 (1985).

17. T. Sarpkaya, 'Hydrodynamic forces on various multiple-tube riser configurations', Proc. Offshore Technology Conference, Houston, Texas, OTC Paper 3539, May 1979, pp. 1603-1606.

18. N.-E. Ottsen Hansen, V. Jacobsen and H. Lundgren, 'Hydrodynamic forces on composite risers and individual cylinders', Proc. Offshore Technology Conference, Houston, Texas, OTC Paper 3541, May 1979, pp. 1607-1622. 